\title{
The Influence of Social Demographic Factors on the Use of Extended Post-Partum Family Planning Methods Among Post-Delivery Women in Tanzania
}

\author{
Rogate Phinias Ibrahim (Corresponding author) \\ Department of Health Systems Management, School of Public Administration and \\ Management, Mzumbe University, P.O.Box 2, Mzumbe, Morogoro, Tanzania \\ E-mail: rophinias@mzumbe.ac.tz
}

\begin{abstract}
Harrieth Mtae $(\mathrm{PhD})$
Department of Community Economic Development, Faculty of Arts and Social Science, Open University of Tanzania, PO Box 23409, Dar Es Salaam, Tanzania

E-mail: mtae.harrieth@out.ac.tz
\end{abstract}

Received: June 8, 2020 Accepted: July 20, 2020 Published: Dec. 31, 2020

doi:10.5296/ijssr.v9i1.18148ＵRL: http://dx.doi.org/10.5296/ijssr.v9i1.18148

\begin{abstract}
Extended Post-Partum Family Planning (EPPFP) refers to the prevention of unplanned and/or closely spaced pregnancies from six (6) weeks to 12 months period after childbirth. It is revealed that $61 \%$ of women in the world do not use effective contraception within 24 months postpartum to prevent unplanned pregnancy. This study examined the influence of social demographic factors on the use of Extended Post-Partum Family Planning (EPPFP) methods among post-delivery women from four selected health care facilities in Tanzania. 255 post-delivery women aged 15-49 years who delivered a child between January 1, 2019 and January 31, 2020 were subjected to a facility-based cross-section study design through convenience sampling. Data were analyzed by SPSS version 20; multiple regression analyses were done to establish the relationships between social demographic factors and the use of Extended Post-Partum Family Planning (EPPFP) methods. It was found that there is a significant relationship between social demographic factors and the use of Extended Post-Partum Family Planning (EPPFP). The study recommends provision of family planning education to the community through mass and social media.
\end{abstract}




\section{Macrothink}

International Journal of Social Science Research

ISSN 2327-5510

2021, Vol. 9, No. 1

Keywords: extended post-partum family planning, social demographic factors, post-delivery women 


\section{Introduction}

Extended Postpartum Family Planning (EPPFP) helps women to get their children spacing need after previous pregnancy (Kaydor et al., 2018). It is said that $90 \%$ of women in the world within the first year of postpartum period wish to either delay or avoid future pregnancies (Mengesha et al., 2015). In the extended postpartum period, there is a large unmet need among women that two-third of these women do not want to find themselves pregnant but do not use any family planning method, whereas, around $40 \%$ of women plan to utilize a family planning method but have not utilized (Ross \& Winfrey, 2001).

World Health Organization (WHO) has recommended women to take at least 24 months interval duration before next pregnancy in order to reduce the undesirable infant and maternal complications; it is also true that still $61 \%$ of women in the world do not use effective contraception within 24 months postpartum to prevent unplanned pregnancy (USAID, 2017). It is argued that, a provision of Extended Postpartum Family Planning (EPPFP) service is of assistance in tackling women's unmet needs for family planning methods in the first year after childbirth and eventually reduces the maternal and infant mortality (Vernon, 2009; Ross \& Winfrey, 2001).

The noted eighty (80) million unplanned pregnancies in the world are directly associated with low utilization of EPPFP and the unmet need for EPPFP among postpartum mothers which is approximately $40 \%$, among all world regions, whereas Sub Saharan region is more liable (Bwazi et al., 2014). This reflects partly the failure to obtain EPPFP soon after giving birth because most of women are exposed to pregnancy 7-9 months after previous birth while they do not desire to become pregnancy that soon, although these women return into menses, they do not abstain from sexual intercourse and are not protected by EPPFP (Winfrey \& Ross, 2001).

According to data analysis of 25 countries as part of Demographic Health Surveys (DHS) project, whereby 12 countries were from Sub-Sahara Africa, 2 countries were from Middle East, 6 countries were from Asia and 5 countries were from Latin America, 17\% of births were conceived within 9 months of preceding births and 35\% conceived within 15 months of the previous birth (Winfrey \& Ross, 2001). A study by Rustein (2000) shows proof from 17 countries in three (3) developing regions and four (4) geographic regions of India that in every country birth intervals are to a large extent shorter than the intended.

This study has used the Health Belief Model (HBM) to explain the influence of social demographic factors on the use of EPPFP methods. As EPPFP use is geared by behavior factors, HBM theory is the best theory towards the use of extended contraceptives because it shows how women can change their behaviors on the way to use EPPFP. The HBM model explains the relationship between the process of change and developing health behavior (Ogden, 2004).

In Tanzania, the prevalence rate of family planning methods is still unsatisfactory as it is $32 \%$ (MoHCDGEC, 2017). According to USAID (2014) just about half (47\%) of all pregnancies that occur yearly in Tanzania are unplanned and occur before the recommended time interval of at least 24 months after delivery. Sixty-four percent (64\%) of all deliveries are aided by skilled health providers in different health facilities; although, the percentage of women who 
use EPPFP in Tanzania is 40\% (MoHCDGEC, 2017).

Furthermore, about $47 \%$ of sexually active women are in danger of getting pregnancy during the first six postpartum months and the danger increases to $68 \%$ among women 6-11 postpartum months. This is because post-delivery mothers do experiencing low sexual desire in the first six (6) months after delivery but in the other postpartum months majority of women $(88 \%)$ becomes sexually active thus increasing risk of getting pregnancy during this postpartum period (USAID, 2014).

There is a significant unmet need of EPPFP among women in Tanzania, studies show that the total unmet need declines as the number of months after delivery increases. From 0-5 postpartum months, the overall unmet need of EPPFP is $81 \%$ which declines to $61 \%$ from 6-11 postpartum months, it further declines to $50 \%$ between 12 and 23 months postpartum (USAID, 2014). The study suggests that women should be subjected to EPPFP counseling during antenatal and postnatal care to increase the demand and use of EPPFP. This is necessary because young women aged 15-19 years in Tanzania (78\%) get pregnancy between 0 to 23 post-delivery months.

In Tanzania, knowledge of Family Planning (FP) services is about 99\% among both male and female, while the utilization of EPPFP services is unfortunately 40\% (TDHS-MIS, 2016). The general objective of the study was to examine the influence of social demographic factors affecting the use of EPPFP services in Mvomero district, Morogoro-Tanzania.

\subsection{Objective of the Study}

The study aimed at examining the association between social demographic factors and the use of Extended Post-Partum Family Planning methods among post-delivery women in Tanzania health facilities.

\subsection{Hypothesis}

The following hypothesis guided the study;

$\mathrm{H}_{\mathrm{o}}=$ There is no significant relationship between social demographic factors and the use of Extended Post-Partum Family Planning methods among post-delivery women in Tanzania health facilities.

$\mathrm{H}_{1}=$ There is significant relationship between social demographic factors and the use of Extended Post-Partum Family Planning methods among post-delivery women in Tanzania health facilities.

\section{Literature review}

\subsection{Post-Partum Family Planning (PPFP)}

The word 'Post-Partum Family Planning (PPFP)' refers to the avoidance of unplanned and/or closely spaced pregnancies in the 12 months period after childbirth (Kaydor et al., 2018). Gebremedhin et al. (2018) defined PPFP as the prevention of unintended pregnancies during the first twelve months following child birth. Soon after delivery, a woman may wish to 
either prevent another pregnancy because she does not need a child anymore, or she may want to prevent another pregnancy for some times until she feels confortable. When she thinks either of the two ideas, it is the best time for her to use PPFP. Therefore, for the purpose of this study, PPFP can be defined as the use of family planning methods in the postpartum period in order to prevent or space pregnancy.

\subsection{Phases of PPFP}

PPFP is offered in any of the three phases namely, Immediate postpartum, Early postpartum and Extended postpartum.

The immediate postpartum is the period where FP is offered to the maternal mother immediately after delivery usually $0-48$ hours following delivery. Early postpartum is the period where FP methods are offered to a maternal mother between 48 hours to 6 weeks following childbirth whereas Extended postpartum is the period where the maternal mother is offered FP method between 6 weeks to 12 months following delivery.

\subsection{Extended Postpartum Family Planning (EPPFP)}

The EPPFP refers to the prevention of unplanned and/or closely spaced pregnancies from six (6) weeks to 12 months period after childbirth (USAID, 2017). The recommended time for PPFP is six (6) weeks to 12 months period after childbirth (Gebremedhin et al., 2018). Most of postpartum women resume to menses and sexual activities between six weeks to twelve months; if they are not protected by EPPFP, they find themselves in the trap of getting unplanned pregnancy and hence maternal and child complications, this is one among the reasons the WHO recommended the use of EPPFP between 6 weeks-12 months following delivery.

\subsection{Influence of Social Demographic Factors on Utilization of PPFP}

The study conducted by Anasel and Mlinga (2014) about the determinants of contraceptive use among married women in Tanzania found women education, discusion of FP with partiners, wealth, religion and husband disapproval of FP to be the main determinants of contraceptive use among married women in the country.

Bwazi et al. (2014) examined factors that determine utilization of postpartum family planning services between six and twelve months of delivery at Ntchisi District Hospital, Malawi; they found adequate knowledge about FP services to women, and 75\% of women used PPFP in the first year past delivery but majority started after resuming menses. Bwazi and the other also found strong relationship between utilization of PPFP services and level of education, period for resuming sex, clarity of FP information given, counseling on fertility intention and husband's approval of FP method.

Blaze and Prata (2016) on their publication on postpartum family planning: current evidence on successful interventions reviewed existing evidence of the usefulness of PPFP interventions of women in the 12 months postpartum period in twenty-six (26) low and middle income countries; They discovered that Male partner involvement, integration with other service delivery platforms, such as prevention of mother-to-child transmission of HIV and 


\section{Macrothink}

immunization, and innovative product delivery programs may increase knowledge and use during the postpartum period.

\section{Method}

The study used facility-based cross-section study design to collect data and hence four health facilities were used which are Mlali, Melela, Mlali mission and Tangeni mission health facilities (Mvomero district, Morogoro). The four health facilities were purposely selected based on the current use of EPPFP and the ownership of the health facility thus Mlali and Melela are public facilities while Mlali mission and Tangeni mission are private facilities. The sample size of 255 post-delivery women was obtained among 700 sampling frames, the sample size was determined using the previously published sample size table (Israel, 2003). Questionnaires were used to collect data to all respondents. All 255 respondents returned the questionnaire which equals to $100 \%$ response rate. Multiple regression analyses were used to test the relationship between socio-demographic factors and the use of EPPFP.

\section{Results}

\subsection{Characteristics of Respondents}

Table 1 shows the mean age of study participants was $26.9(\mathrm{SD} \pm 6.017)$ and the minimum and maximum age was 18 and 43 respectively. Majority of the respondents 211, $110(43 \%)$ and $111(43.4 \%)$ were between 15-24 and 25-34 years of age respectively. A total of 198 $(77.3 \%)$ respondents were married, both mothers and their husbands $177(69.8 \%)$ and 178 (72\%) respectively had primary level of education, nearly half of mothers $114(44.5 \%)$ were doing small businesses and majority of them 136 (53.1\%) were Christians, majority of respondents $161(62.9 \%)$ were wished to have less than four (4) children and most of respondents $86(33.6 \%)$ had two living children. 


\section{Macrothink}

Table 1 Social demographic characteristics of study participants $(\mathrm{N}=256)$

\begin{tabular}{llll}
\hline Variable & Sub variable & Frequency & Percent \\
\hline Age & $15-24$ & 110 & 43.0 \\
& $25-34$ & 111 & 43.4 \\
Marital status & $35-44$ & 35 & 13.7 \\
Education level of a maternal mother & Married & 198 & 77.3 \\
& Not married & 58 & 22.7 \\
& No formal education & 2 & .8 \\
& Primary & 177 & 69.1 \\
& Secondary & 61 & 23.8 \\
Spouse's Education level & Tertiary & 16 & 6.3 \\
& No formal education & 2 & .8 \\
& Primary & 178 & 72.4 \\
& Secondary & 50 & 20.3 \\
Religion & Tertiary & 16 & 6.5 \\
Occupation of client & Christian & 136 & 53.1 \\
& Muslim & 120 & 46.9 \\
& Employed, & 32 & 12.5 \\
& Small business, & 114 & 44.5 \\
& Farming, & 62 & 24.2 \\
& Housewife & 48 & 18.8 \\
\hline
\end{tabular}

Source: Field data, 2020.

\subsection{Multiple Regressions}

The study had an assumption that there is a relationship between social demographic factors and EPPFP utilization. Multiple regression analysis was used to provide a model that can explain the existing relationship between variables. The regression model used was as follows;

$$
\mathrm{Y}=\mathrm{a}+\mathrm{b}_{1} \mathrm{X}_{1}+\mathrm{b}_{2} \mathrm{X}_{2}+\mathrm{b}_{3} \mathrm{X}_{3}+\mathrm{e}
$$

Where:

$\mathrm{Y}=\mathrm{EPPFP}$ use,

$\mathrm{a}$ and $\mathrm{b}=$ regression constants,

$\mathrm{a}=$ the $\mathrm{Y}$ intercept when $\mathrm{X}$ is zero,

$\mathrm{b} 1, \mathrm{~b} 2$ and $\mathrm{b} 3=$ regression weights attached to the variables,

$\mathrm{X}_{1}=$ age of a mother,

$\mathrm{X}_{2}=$ education level of a mother,

$\mathrm{X}_{3}=$ Work status of a mother, 
$\mathrm{e}=$ error term.

\subsubsection{Evaluating the Model}

The researcher sought to understand the extent of influence of independent variables (age of a mother, education level of a mother and work status of a mother) on the dependent variable (EPPFP utilization). The ' $\mathrm{R}$ square' is a measure of how much the variance in the dependent variable is explained by the model. Table summarizes the results.

Table 2. Model summary

\begin{tabular}{lllll}
\hline Model & $\mathrm{R}$ & R Square & Adjusted R Square & Std. Error of the Estimate \\
\hline 1 & $.941^{\mathrm{a}}$ & .885 & .884 & .170 \\
\hline
\end{tabular}

Note. a. Predictors: (Constant), Work status, Age, School levels.

Table 2 shows that the 'R square" value is 0.885 , which means that the extent of the influence of independent variables (age of a mother, education level of a mother and work status of a mother) on the dependent variable (EPPFP utilization) is $88.5 \%$. Such a percentage indicated a high level of prediction, that $88.5 \%$ of the variations in EPPFP use could be explained by the changes in age, education level and work status. The $11.5 \%$ unexplained percent goes for other factors. Based on the findings it can be argued that the utilization of EPPFP is greatly influenced by social demographic factors.

\subsubsection{Analysis of Variance (ANOVA) Test}

To understand overall significance of independent variables in predicting dependent variables, the ANOVA test was performed and the results were as shown in Table 3.

Table 3. ANOVA test

\begin{tabular}{lllllll}
\hline ANOVA $^{\mathbf{a}}$ & \multicolumn{1}{l}{} \\
\hline Model & & Sum of Squares & df & Mean Square & F & Sig. \\
\hline 1 & Regression & 56.308 & 3 & 18.769 & 647.760 & $.000^{\mathrm{b}}$ \\
& Residual & 7.302 & 252 & .029 & & \\
& Total & 63.609 & 255 & & & \\
\hline
\end{tabular}

Note. a. Dependent Variable: EPPFP use; b. Predictors: (Constant), age of a mother, education level of a mother and work status of a mother.

Table 3 shows that in overall the independent variables (age of a mother, education level of a mother and work status of a mother) are significant in predicting the dependent variable (EPPFP use). Therefore, there is a significant relationship between social demographic factors and the use of Extended Post-Partum Family Planning methods among post-delivery 
women in health facilities. This is evidenced by sig 0.000 , P-value which is less than 0.05 .

\section{Discussion}

Social demographic factors can either increase or reduce the demand for EPPFP to women; this idea is clearly discussed by the Health Belief Model (HBM), the model argues that there are three factors that influence a person's decision to take EPPFP methods, one among them is predisposed characteristics such as demographic factors and social structure. This study as well assessed social demographic factors including age, education, marital status and work status in relation to utilization of EPPFP. Age, education level and mother's occupation showed significant association with the use of EPPFP, P-value of $0.000,0.000$ and 0.000 respectively.

The age of a woman may prompt a woman to use EPPFP methods, the study found there was higher use of EPPFP methods among women with age between 15 to 34 years; this implies that EPPFP uptake was higher among younger women compared to the older women. This might be due to their sexual activeness. This finding is similar to the study conducted in Uganda by Rutaremwa et al. (2015) on the predictors of modern contraceptive use during postpartum period among women, which argued that the PPFP use was significantly reduced by an increment in women's age. However, their study was done to married women only while the present study was conducted to both married and unmarried women.

In fact, it was very important to understand the education status of a woman because education plays a big role in one's perception, attitude and finally practice on EPPFP use. Literate education status of postpartum women was associated with EPPFP use, this result was similar to the study titled postpartum family planning utilization and associated factors among women who gave birth in the past 12 months, Kebribeyah Town, Somali Region, Eastern Ethiopia conducted by Nigussie et al. (2016), they found that literate postpartum women were more likely to use PPFP as compared to illiterate. The same result was also observed by Rutaremwa et al. (2015). However, their studies found higher number of women with secondary and tertiary education in comparison to the present study which found majority of women with primary education. The reason for this association might be due to the fact that education increases the level of understanding and awareness of FP and hence better understanding and choice of the available methods of family planning during postpartum period.

Respondent's occupation has been one among the predictor of EPPFP utilization. Majority of respondents were doing small businesses. In fact, results revealed a woman was likely to use EPPFP method when she works outside and earn something, majority of women who were doing small businesses were found using EPPFP compared to those who do not work outside their homes (housewives) with nothing to earn from themselves. This study is similar to the study conducted by Anasel and Mlinga (2014) about the determinants of contraceptive use among married women in Tanzania which found women education, wealth, religion and husband disapproval of FP to be main determinants of contraceptive use among married women in the country. Other studies also found a large number of working women using PPFP with the reason that since they were earning income, they were having greater control 
over household decisions particularly reproductive decisions (Hialemariam et al., 1999; Gage, 1995)

Despite the fact that majority of post-delivery women were married, the study found that being married or unmarried woman was not the reason for taking EPPFP. These results were dissimilar to the community-based cross-sectional study done by Gebremedhin et al. (2018) concerning family planning use and its associated factors among women in the extended postpartum period in Addis Ababa-Ethiopia, they found marriage had a positive relationship with PPFP use to post delivery women that unmarried women were less likely to use PPFP than married women. Possible reasons for this difference might be due to cultural variations as in Tanzania it is moraly wrong for a young woman to get pregnancy before getting marriage, the family feels ashamed and fear that they are daughter will not get married but she will add more children at home, so women strive to use EPPFP to prevent additional pregnancy, concurrently it is a prestige for the married women to bear many children so this might make married women not to use EPPFP. Another posssible reason might be service accessibility, umarried women can have more access to EPPFP services than married women because majority of married women get oppositions from their spouses and their bound to husband's decisions while unmarried women have no restrictions.

The spouse's education level showed insignificant association with the use of EPPFP among women in extended postpartum period. This study was unrelated to the study done by Mangesha et al. (2015) entitled as contraceptive adoption in the extended postpartum period is low in Nothern Ethiopia,who found higher education of husbands promoted the use of contraceptives. This difference might be due to the social demographic differences because the current study found majority of postpartum women together with their husbands had the same level of education that was primary education; possibly the difference could be minimized when the husbands' level of education was higher than their wives as men play a great role on decision about family planning issues for their wives.

\section{Conclusion}

The study found the use of EPPFP among post-delivery women was influenced by social demographic factors such as age, education level and working status of a woman. The study recommends provision of family planning education to the community through mass and social media.

\section{Acknowledgments}

We express our sincere appreciation to the Mlali, Mlali mission, Tangeni mission and Melela health facilities for the support they showed us during the whole time of data collection.

\section{References}

Anasel, M., \& Mlinga, U. (2014). Determinants of contraceptive use among married women in Tanzania: Policy implication. African Population Studies, 34(2). https://doi.org/10.11564/28-0-550

Blaze, C., \& Prata, N. (2016). Postpartum family planning: Current evidence on successful 
interventions. Open Access Peer-Reviewed Scientific and Medical Journals, 53-67. https://doi.org/10.2147/OAJC.S98817

Borda, M., \& Winfrey, W. (2010). Post-partum fertility and contraception: An analysis of finding from 17 countries. Baltimore, Maryland, USA: Jhpiego.

Bwazi, C. (2014). Utilization of Postpartum Family Planning Services between Six and Twelve Months of Delivery at Ntchisi District Hospital, Malawi. Scientific Research Journal, 6(14), 1724-1737. https://doi.org/10.4236/health.2014.614205

DHS-2. (2019). The report of FP, ANC, Health facilities deliveries of Mvomero District for the year 2015, 2016, 2017 and 2018. Morogoro.

Gebremedhin, K., \& Galagay, H. (2018). Family planning use and its associated factors among women in the extended postpartum period in Addis Ababa, Ethiopia. Contraception and Reproductive Medicine. https://doi.org/10.1186/s40834-017-0054-5

Gejo, N. G., Anshebo, A. A., \& Dinsa, L. H. (2019). Postpartum modern contraceptive use and associated factors in Hossana town. Plos ONE. https://doi.org/10.1371/journal.pone.0217167

Israel, G. D. (2003). Determining sample size (pp. 2-3).

Kabagenyi, G., \& Rutaremwa, A. N. (2015). Postpartum family planning utilization in Burundi and Rwanda: A comparative analysis of population based cross-sectional data. Addis Ababa.

Kaydor, V. K., Adeoye, I. A., Olowolafe, T. A., \& Adekunle, A. O. (2018). Barriers to acceptance of post-partum family planning among women in Montserrado County, Liberia. Niger Postgrad Med J., 25, 143-148.https://doi.org/10.4103/npmj.npmj_96_18

Kothari \& Garg. (2014). Research Methodology: Methods and Techniques. New Delhi: New Age International.

Mackfallen, A. (2017). Family Planning Programme Implementation. Moshi: ISBN978-94-91676-03-1 (print).

Mengesha, B. N., Worku, G. A., \& Feleke, A. S. (2015). Contraceptive adoption in the extended postpartum period is low in Northwest Ethiopia. BMC Pregnancy \& Childbirth, 1-6. https://doi.org/10.1186/s12884-015-0598-9

MoHCDGEC. (2016). The National Road Map Strategic Plan to Improve Reproductive, Maternal, Newborn, Child \& Adolescent health in Tanzania (2016-2020) One Plan II. Dar es salaam: MoHCDGEC.

MoHCDGEC. (2017). National Family Planing Procedure Mannual. Dar es Salaam: MoHCDGEC.

Nigussie, A., Girma, D., \& Tura, G. (2016). Postpartum Family Planning Utilization and Associated Factors among Women who Gave Birth in the Past 12 Months, Kebribeyah Town, Somali Region,Eastern Ethiopia. Journal of Women's Health Care.

Rutaremwa, G., Kabagenyi, A., Wandera, S. O., \& Jhamba, T. (2015). Predictors of modern 
contraceptive use during the postpartum period among women in Uganda: A population-based cross sectional study. BMC Public Health, 15. https://doi.org/10.1186/s12889-015-1611-y

Singh, M. (2015). Awareness and acceptance of contraception in post-partum women. International Journal of Reproduction, Contraception, Obstetrics and Gynecology, 690-695. https://doi.org/10.18203/2320-1770.ijrcog20150075

TCCP. (2016). Tanzania Capacity and Communication Project (TCCP). Retrieved October 9, 2019, from https://www.thecompassforsbc.org/sites/default/files/project_examples/TCCP\%20Overview. pdf

TDHS-MIS. (2016). Tanzania Demographic Health Survey and Malaria Indicator Survey, 2015-2016. Dar es Salaam.

Thamini Uhai. (2016). Tanzania Maternal Health Program. Dar es Salaam.

UNICEF. (2018). Tanzania - Maternal \& child health - The situation. Dar-es-salaam: UNICEF Tanzania.

USAID. (2014). Family Planning Needs during the First Two Years Postpartum in Tanzania. Washington DC: USA.

USAID. (2017). Postpartum contraceptives; Family planning methods and Child spacing after childbirth.

Vernon, R. (2009). Meeting the Family Planning Needs of Postpartum Women. JSTOR, 40(3), 235-245. https://doi.org/10.1111/j.1728-4465.2009.00206.x

World Health Organization (WHO). (2013, November 13). apps.who.int. Retrieved December 18, 2018, from https://www.who.int

World Health Organization (WHO). (2018, 7, 28). Programming strategies for postpartum family planning. Retrieved from http://apps.who.int/iris/bitstream/10665/93680/1/9789241506496_eng.pdf

World Health Organization (WHO). (2019). Maternal, newborn, child and adolescent health. Retrieved from https://www.who.int/maternal_child_adolescent/topics/maternal/maternal_perinatal/en/

World Health Organization (WHO). (2019, December 12). Reproductive health family_planning-unmet_need_fp. Retrieved from https://www.who.int

\section{Copyrights}

Copyright for this article is retained by the author(s), with first publication rights granted to the journal.

This is an open-access article distributed under the terms and conditions of the Creative Commons Attribution license (http://creativecommons.org/licenses/by/4.0/). 